www.jmscr.igmpublication.org

Impact Factor (SJIF): 6.379

Index Copernicus Value: 71.58

ISSN (e)-2347-176x ISSN (p) 2455-0450

crossrefDOI: https://dx.doi.org/10.18535/jmscr/v6i7.36

\author{
D) Journal Of Medical Science And Clinical Research \\ IGM Publication \\ An official Publication of IGM Publication
}

\title{
Presentation, Etiology and Management of Obstructive Jaundice: A Prospective Study
}

\author{
Authors \\ Nilesh P. Mangam", Dr Sanjay D. Dakhore ${ }^{2}$, Rithesh M. Bodade ${ }^{3}$, Asmita S. Dhurve ${ }^{4}$, \\ Amol P. Dhoran 5 \\ 1,2,3,4,5 Assistant Professor, Department of Surgery, Government Medical College and Hospital, Nagpur, \\ Maharashtra, India \\ Corresponding Author \\ Dr Sanjay D. Dakhore \\ Assistant Professor, Department of Surgery, Government Medical College and Hospital Nagpur, \\ Maharashtra, India
}

\begin{abstract}
Introduction: Obstructive jaundice is caused by defective transport of conjugated bilirubin from hepatic cells to the second part of duodenum. It is not a diagnosis in itself and varied etiologies may be responsible for obstructive jaundice. It is important to diagnose the cause of obstructive jaundice because delay in diagnosis may cause irreversible pathological changes. The diagnosis of obstructive jaundice usually is done by biochemical tests, imaging and in some cases by histopathology. Management depends upon the etiology. Many cases of extra hepatic biliary obstruction are amenable to surgery if diagnosed at an appropriate time. We conducted this study to know etiology, clinical presentation and management outcome of the patients diagnosed to have obstructive jaundice.

Materials and Methods: This was a prospective study conducted in the department of surgery of a tertiary care medical college situated in an urban area. Patients above the age of 18 years who were admitted and diagnosed to have obstructive jaundice were included in this study depending upon a predefined inclusion and exclusion criteria. The diagnosis was confirmed by Imaging. Ultrasonography was done in all cases. Computed Tomography, MRCP, ERCP and biopsy were done in selected cases. Treatment outcome and complications were noted in all the cases. The data was analyzed using SSPE 16 software. P value less than 0.05 was taken as significant for statistical purposes.

Results: The study consisted of 106 patients of obstructive jaundice out of which male patients were $58(54.71 \%)$ and female patients were $48(45.28 \%)$. The male to female ratio was 1.2: 1.the incidence of obstructive jaundice was highest in the age group of 51-60 years.the most common symptom was jaundice which was present in all 106 patients (100\%). The other common symptoms were pain in abdomen (68.86\%), loss of appetite (59.43\%), loss of weight (57.54\%) and itching (41.50\%). Most common sign was icterus (100\%) followed by abdominal tenderness (50.94\%), itching marks (41.50\%) and palpable gall bladder (39.62\%). The most common finding on ultrasound as well as CT was found to be dilated common bile duct. Choledocholithiasis was found to be the most common benign cause of obstructive jaundice (32.07\%) while most common malignancy causing obstructive jaundice was carcinoma head of pancreas (29.24\%). Interventions included common bile duct exploration, stenting and cholecystojejunostomy. Surgical bypass and endoscopic stenting was done in 33 and 16 patients respectively. The most common post-operative complication in studied cases was found to be wound infection (5.66\%) followed by cholangitis (3.77\%) and septicemia (2.83\%).

Conclusion: Obstructive jaundice is one of the common causes of surgically amenable jaundice. Its etiology is varied and diagnosis usually depends upon appropriate imaging. Proper diagnosis and treatment is necessary as delay in the diagnosis may cause irreversible pathological changes causing increased morbidity and mortality.
\end{abstract}

Keywords: Obstructive jaundice, Imaging, Surgical Interventions, Complications. 


\section{Introduction}

Obstructive Jaundice by definition is due to pathologies causing obstruction to the passage of conjugated bilirubin from hepatocyte to intestine ${ }^{1}$. It is one of the common causes of jaundice for which surgical consultation is sought. If not diagnosed in time and treatment is delayed then there is a high morbidity and mortality in the patients with obstructive jaundice ${ }^{2}$. In malignant diseases causing obstructive jaundice early diagnosis and timely resection will be one of the important determinant of prognosis and late diagnosis may be associated with unresectability of primary tumor ${ }^{3}$. Even in benign pathologies late diagnosis may be associated with irreversible pathological changes such as secondary biliary cirrhosis.

The etiology of obstructive jaundice varies greatly depending upon the geographical region as well as age of the patients. In neonates the common causes of obstructive jaundice include biliary atresia and neonatal hepatitis while in young and middle age patients common causes include cholelithiasis, primary sclerosing cholangitis, external compression over bile duct and biliary stricture. With advancing stages the likelihood of malignant diseases such as cholangiocarcinoma, carcinoma head of pancreas and any other malignant growth compressing over bile duct increases.

Some of the common causes of obstructive jaundice can be very effectively treated by surgery hence sometimes its referred to as surgical jaundice. Results of surgery in some of these cases are dramatic. A vast array of invasive and noninvasive diagnostic tests is available to diagnose and establish the etiology of surgical obstructive jaundice ${ }^{4}$. Invasive tests may cause cholangitis and imaging techniques like computed tomography (CT) scan, PTC, ERCP and MRCP are expensive and are not readily available in most centers in developing countries, and ultrasonography remains the only diagnostic test available ${ }^{5}$.The management of obstructive jaundice poses diagnostic and therapeutic challenges to general surgeons practicing in resource-limited countries ${ }^{6}$. Late presentation of the disease coupled with lack of modern diagnostic and therapeutic facilities are among the hallmarks of the disease in developing countries. Surgery in jaundiced patients is associated with a higher risk of postoperative complications compared with surgery in non-jaundiced patients ${ }^{7}$. These complications primarily consist of septic complications (cholangitis, abscesses, and leakage), hemorrhage, impaired wound healing and renal disorders ${ }^{8}$.

The outcome of treatment of obstructive jaundice may be poor especially in developing countries where advanced diagnostic imaging and therapeutic facilities are not readily available in most centers. The mortality and morbidity of biliary obstruction are dependent on the cause of the obstruction, and the assessment of any factors which influence the morbidity and mortality in patients with obstructive jaundice in each society is necessary. Understanding factors responsible for increased morbidity and mortality in these patients will better guide appropriate management and lead to improved survival. There is paucity of information regarding the management of obstructive jaundice in our environment as there is no local study which has been done in our setting particularly the study area'

This study was undertaken to describe our own experiences in the management of obstructive jaundice, outlining the etiological spectrum, treatment outcome and prognostic factors for morbidity and mortality in our local setting.

\section{Materials and Methods}

This was a prospective observational study which was conducted in the surgery department of a tertiary care medical college situated in an urban area. Institutional ethical committee approved the study. Patients diagnosed to be having obstructive jaundice and treated in this department were included in this study on the basis of a predefined inclusion and exclusion criteria. Informed consent was obtained from all the patients. area. A total of 
106 cases of obstructivejaundice were included in this study. Detailed history of the patients along with demographicdetails was noted down. A complete general and systemicexamination was done. Any past history of jaundice was asked and noted. History of drug intake was also noted. All the patients were studied with respect to the presenting complaints and signs. Routine investigations like blood group, complete bloodcount, liver function tests, kidney function tests, blood sugarlevel, urine analysis, Liver function tests and coagulation profile was done in allthe cases. Ultrasonography was done in all the cases. Other investigations like Computerized Tomography, Magnetic resonance imaging, Endoscopic retrograde cholangio-pancreatography (ERCP) and Percutaneous transhepatic cholangiography (PTC) was done in selected cases. Biopsy or FNAC was done when histopathological confirmation was needed. Etiology of the obstructive jaundice was determined on the basis of imaging. Appropriate surgical interventions were done on the basis of etiology of obstructive jaundice, age of the patient and according to the standard protocol. Postoperative complications were noted in all the cases. Patients were followed up at least for 3 months. The data was analyzed using SSPE 16.0 version software. Microsoft Excel was used for preparing charts and graphs.

\section{Inclusion Criteria}

1. All the patients who have been admitted in department of surgery and diagnosed to be having obstructive jaundice.

2. Age of the patients should be more than 18 years.

3. Those who have given informed consent to be part of the study.

\section{Exclusion Criteria}

1. Patients who refused consent.

2. Patients less than 18 years of age.

3. Patients who were unfit for interventional or surgical management.

\section{Results}

Out of 106 patients treated for obstructive jaundice the numbers of male patients were 58 $(54.71 \%)$ and female patients were 48(45.28\%). The male to female ratio was 1.2: 1 .

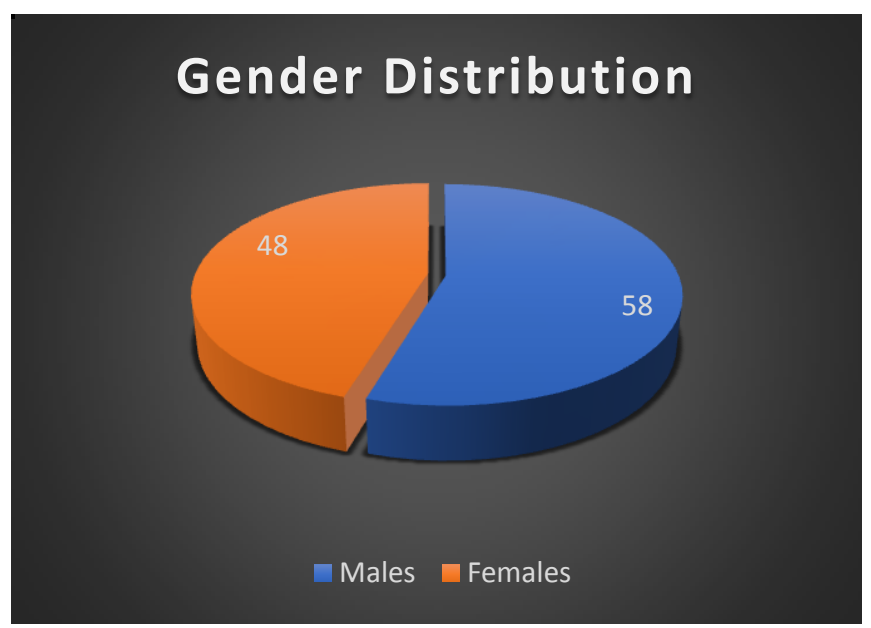

Figure 1: Gender Distribution of the studied cases.

The analysis of the age groups of the patients showed that the incidence was highest in the age group 51-60 years. The second most common age group was 41-50 years. The youngest patient was a 18 years old male. There were 5 patients who were elder than 70 years of age. In patients with benign etiology approximately $67.56 \%$ patients were above 40 years of age while in case of malignant causes $81.15 \%$ patients were above 40 years of age.

Table 1: Age groups of the studied cases

\begin{tabular}{|l|c|c|}
\hline Age Group & No of Patients & Percentage \\
\hline $18-30$ & 07 & $6.60 \%$ \\
\hline $31-40$ & 17 & $16.03 \%$ \\
\hline $41-50$ & 28 & $26.41 \%$ \\
\hline $51-60$ & 33 & $31.13 \%$ \\
\hline $61-70$ & 16 & $15.09 \%$ \\
\hline 71 and above & 05 & $4.71 \%$ \\
\hline Total & 106 & $100 \%$ \\
\hline
\end{tabular}

The analysis of symptoms of the patients showed that the most common symptom was jaundice which was present in all 106 patients (100\%). The other common symptoms were pain in abdomen (68.86\%), loss of appetite $(59.43 \%)$, loss of weight $(57.54 \%)$ and itching $(41.50 \%)$. 
Table 2: Symptomatology in the studied cases

\begin{tabular}{|l|c|c|}
\hline Symptoms & No of Patients & Percentage \\
\hline Jaundice & 106 & 100 \\
\hline Itching & 44 & 41.50 \\
\hline Pain in abdomen & 73 & 68.86 \\
\hline Lump in abdomen & 08 & 7.54 \\
\hline Loss of weight & 61 & 57.54 \\
\hline Loss of appetite & 63 & 59.43 \\
\hline Fever & 19 & 17.92 \\
\hline Distension of abdomen & 14 & 13.20 \\
\hline Clay colored stool & 39 & 36.79 \\
\hline Malena & 10 & 9.43 \\
\hline
\end{tabular}

The analysis of signs in the studied cases showed that the most common sign was icterus which was present in all the cases (100\%). The other common signs present in the studied cases were abdominal tenderness (50.94\%), itching marks $(41.50 \%)$ and palpable gall bladder (39.62\%).

Table 3: Clinical signs in the studied cases

\begin{tabular}{|l|c|c|}
\hline Sign & No of Patients & Percentage \\
\hline Icterus & 106 & 100 \\
\hline Itching marks & 44 & 41.50 \\
\hline Palpable gall bladder & 42 & 39.62 \\
\hline Hepatomegaly & 40 & 37.73 \\
\hline Tenderness & 54 & 50.94 \\
\hline Free fluid & 08 & 7.54 \\
\hline P/R clay colored stool & 39 & 36.79 \\
\hline
\end{tabular}

All patients (100\%) underwent ultrasonography. Other investigations like Computerized Tomography $(780 \%)$, Magnetic resonance cholangio-pancreatography (21.69\%), Endoscopic retrograde cholangio-pancreatography (23.58\%) and Percutaneous transhepatic cholangiography (5.66\%) was done in selected cases. Fine needle aspiration and bile cytology was done in 4 $(4.71 \%)$ and $3(2.83 \%)$ patients respectively.

Table 4: Investigations in the studied cases

\begin{tabular}{|l|c|c|}
\hline Investigation & No of Patients & Percentage \\
\hline USG & 106 & $100 \%$ \\
\hline CT & 83 & 78.30 \\
\hline MRCP & 23 & 21.69 \\
\hline ERCP & 25 & 23.58 \\
\hline PTC & 6 & 5.66 \\
\hline FNAC & 5 & 4.71 \\
\hline Bile cytology & 3 & 2.83 \\
\hline
\end{tabular}

The ultrasound was done in all the cases. The most common finding on ultrasound was found to be dilated common bile duct $(73.58 \%)$ followed by dilated intrahepatic biliary radicals $(66.98 \%)$ and distended gall bladder (45.28\%). The other less common ultrasound findings in the studied cases were found to be dilated pancreatic duct (15.09\%), secondaries in liver (10.38\%), free fluid in abdomen $(7.55 \%)$ and lymphadenopathy $(4.72 \%)$.

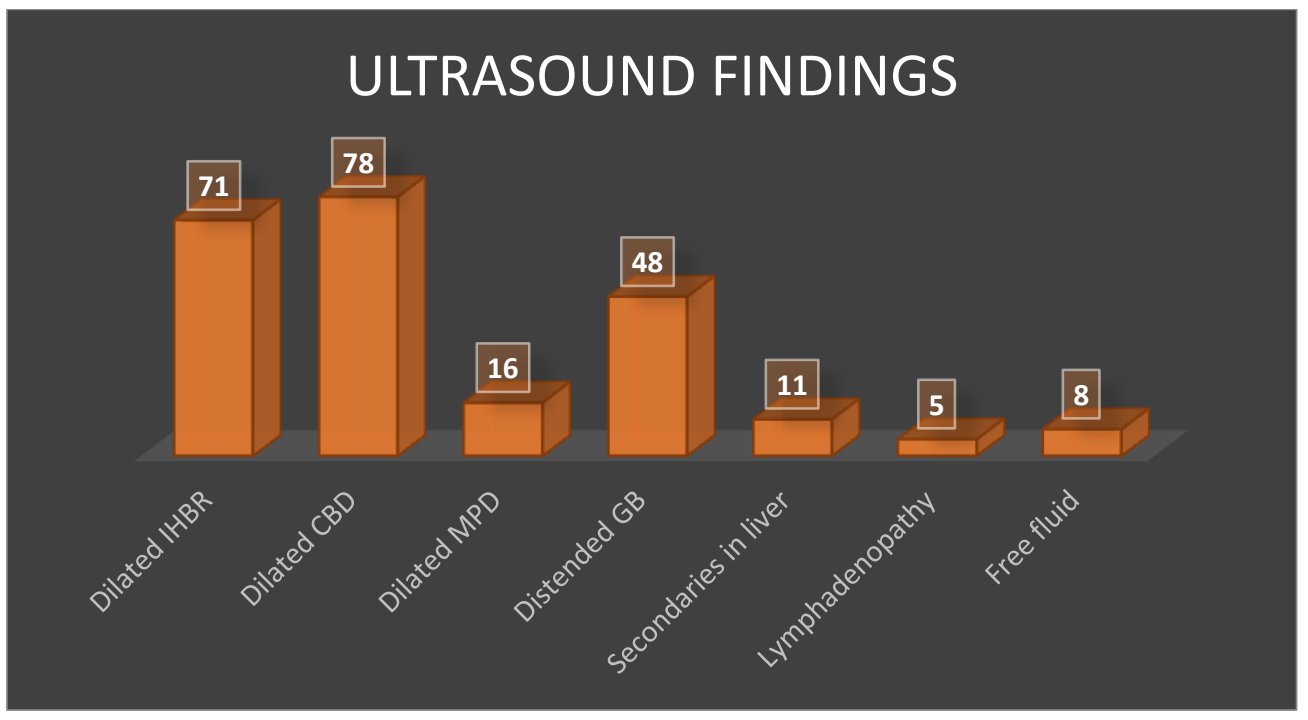

Figure 2: Ultrasound findings in the studied cases

CT abdomen was done in 83 patients. Out of these 83 cases the most common finding was found to be dilated common bile duct $(93.98 \%)$ followed by dilated intrahepatic biliary radicals $(85.54 \%)$ and distended gall bladder (57.83\%). Secondaries in liver were seen in 13 patients (15.66\%). 2 patients in whom ultrasound couldn't pick up hepatic secondaries were diagnosed on the basis of computerized tomography. 


\section{CT FINDINGS}

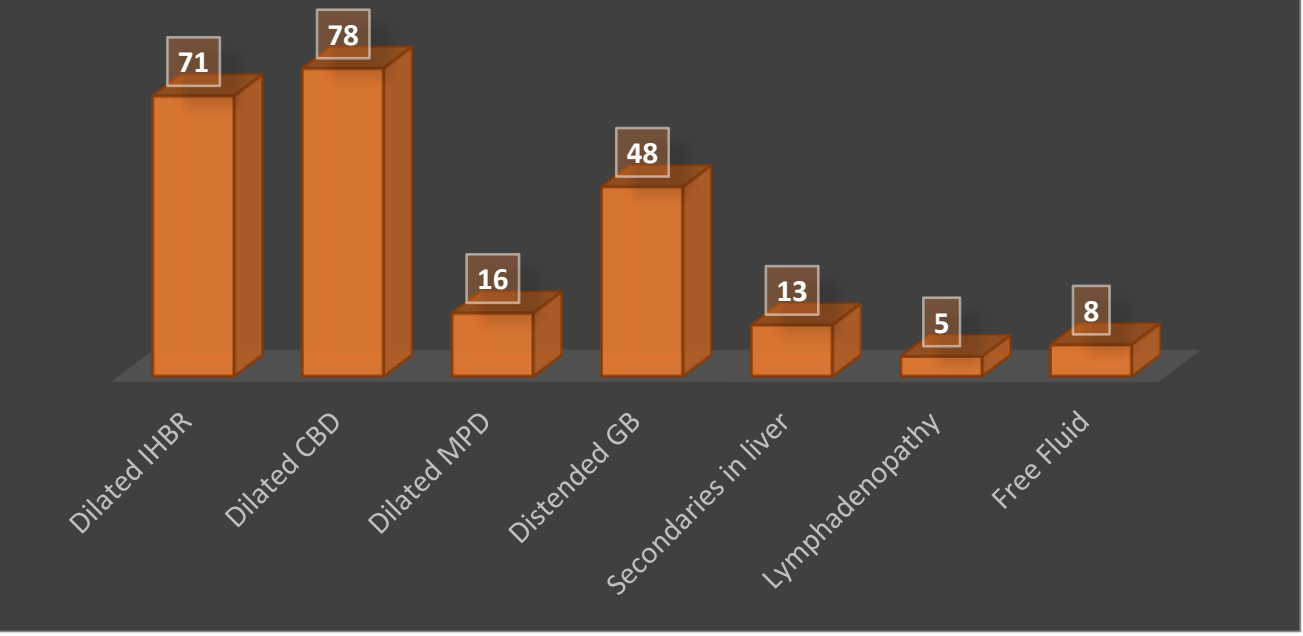

Figure 3: CT findings in the studied cases

In the present study, the most common cause for malignant obstructive jaundice was carcinoma ahead of pancreas (29.24\%) followed by carcinoma of ampulla or periampullary duodenum which was seen in 20 patients (18.86\%). Cholangio carcinoma was seen in 10 patients. In 6 patients cause was gallbladder malignancy and 2 patients had Klatskins tumor. Amongst the benign diseases choledocholithiasis was found to be leading cause and was seen in 34 patients. In 2 patients benign biliary stricture was the cause of obstruction. The incidence of choledocholithiasis was similar in male and female patients in this study. The incidence of $\mathrm{Ca}$ head of pancreas, cholangio-carcinoma and carcinoma of ampulla was more in male than female patients.

\section{ETIOLOGY OF OBSTRUCTIVE JAUNDICE}

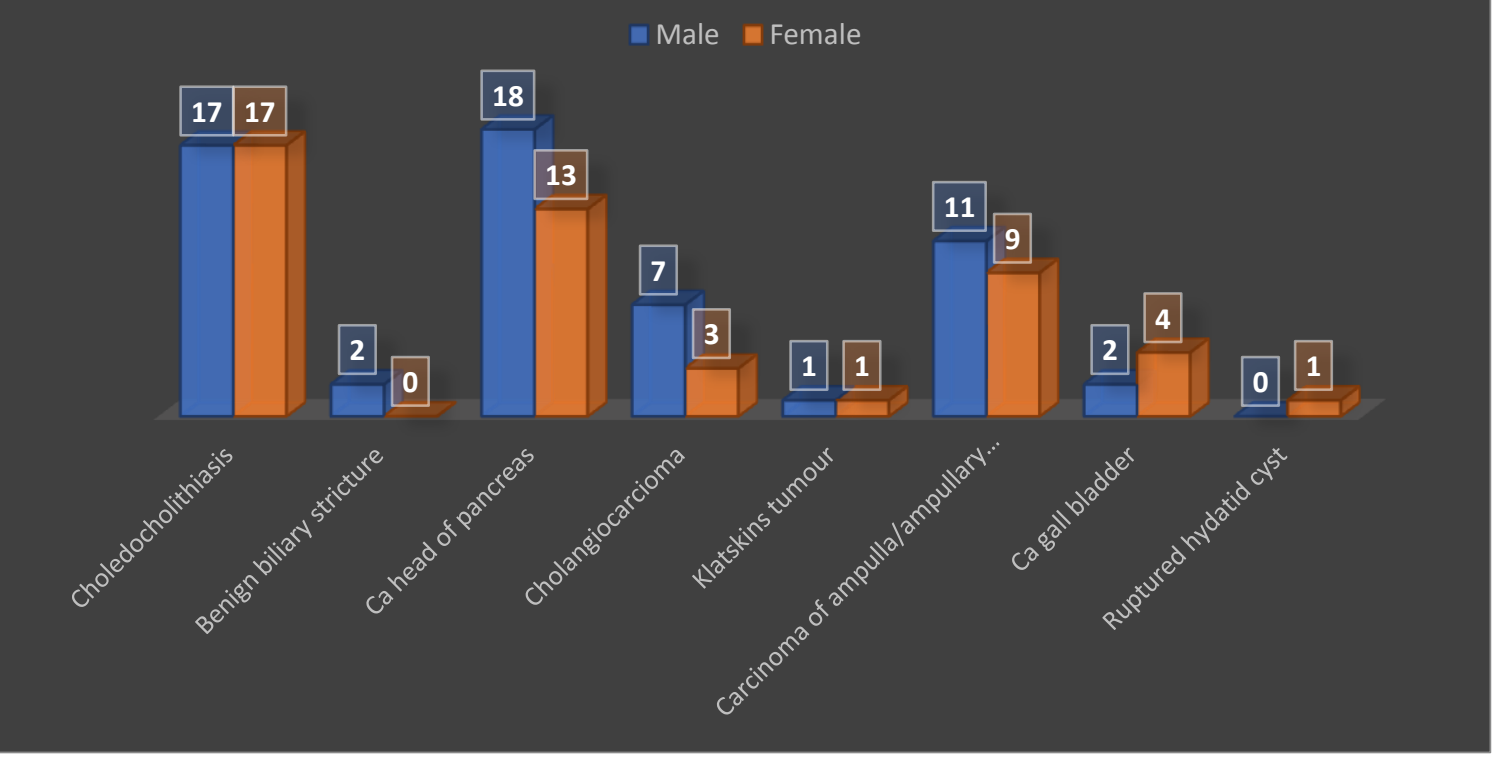

Figure 4: Etiological causes of obstructive jaundice in the studied cases.

Out of the 37 patients with benign etiologies, 25 patients underwent common bile duct (CBD) exploration for gall bladder and CBD calculi, 17 of them underwent cholecystectomy with CBD exploration, 9 patients with CBD calculi underwent endoscopic interventions. Percutaneous Transhepatic Biliary Drainage (PTBD) was done in 2 patients with distal CBD 
stricture as these patients were poor candidates for surgery. In the patients with ruptured hydatid cyst cholecystojejunostomy was done.

In patients with jaundice of malignant causes, procedures were carried out with therapeutic and palliative intent. Whipple's procedure was performed in 18 patients. In 32 patients, surgical palliation was done with cholecystojejunostomy (20 patients), choledochojejunostomy (8 patients), and hepaticojejunostomy (4 patients). Endoscopic stenting as palliative measure was used in 16 patients. Percutaneous transhepatic biliary drainage was done in 4 patients. Chemotherapy and radiotherapy was given to 30 patients.

\section{INTERVENTIONS IN OBSTRUCTIVE JAUNDICE}

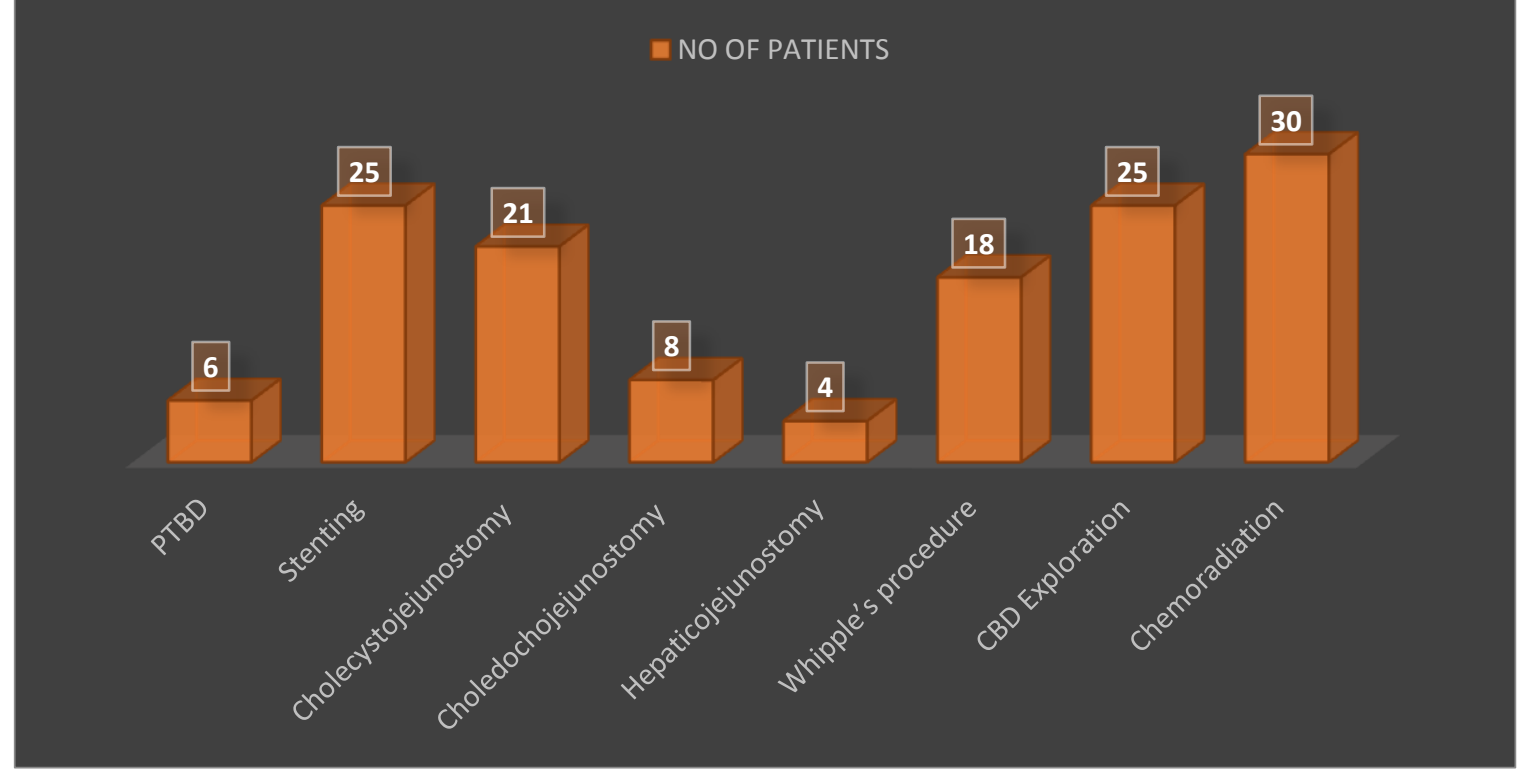

Figure 5: Interventions done in the studied cases

The analysis of the patients on the basis of the treatment showed that the duration of the hospital stay was statistically significantly less in patients in whom endoscopic stenting was done than in patients in whom surgical bypass was done $(5.43 \pm 1.59 \mathrm{Vs} 13.27 \pm 2.33$ days). The other factors such as age of the patients, serum bilirubin and alkaline phosphatase values were comparable and there was no statistically significant difference in both the groups.

Table 5: Comparison of patients treated by surgical bypass and endoscopic stenting

\begin{tabular}{|l|c|c|c|}
\hline & $\begin{array}{c}\text { Surgical } \\
\text { bypass }\end{array}$ & $\begin{array}{c}\text { Endoscopic } \\
\text { stenting }\end{array}$ & p value \\
\hline No of patients & 33 & 16 & - \\
\hline Male & 17 & 9 & - \\
\hline Female & 16 & 7 & - \\
\hline Age & $50.75 \pm 12.63$ & $49.43 \pm 8.97$ & $0.71(\mathrm{NS})$ \\
\hline Serum bilirubin & $14.07 \pm 9.54$ & $15.26 \pm 5.87$ & $0.6505(\mathrm{NS})$ \\
\hline Serum Alk. Po4 & $618.48 \pm 139.84$ & $600.5 \pm 98.99$ & $0.6474(\mathrm{NS})$ \\
\hline Hospital stay & $13.27 \pm 2.33$ & $5.43 \pm 1.59$ & $0.00(\mathrm{~S})$ \\
\hline
\end{tabular}

The most common post-operative complication in studied cases was found to be wound infection (5.66\%) followed by cholangitis $(3.77 \%)$ and septicemia $(2.83 \%)$. The other less common complications included anastomotic leak (1.89\%), Biliary peritonitis (1.89\%), pleural effusion (1.89\%) and dyselectrolytemia (1.89\%). Stent occlusion or dislodgement was seen in $2(1.89 \%)$ patients.Patients with biliary peritonitis were treated conservatively. Anastomotic leak and electrolyte imbalance was seen in 2 patients who were died in due course. 2 patients who had stenting done was readmitted for stent dislodgement and underwent laparotomy for the same. Pleural effusion, which was seen in 2 patients, was treated with antibiotics and chest physiotherapy. 3 patients developed septicemia and were started on higher antibiotics. 
Table 6: Comparison of patients treated by surgical bypass and endoscopic stenting

\begin{tabular}{|l|c|c|}
\hline Complication & No of patients & Percentage \\
\hline Anastomotic leak & 02 & $1.89 \%$ \\
\hline Biliary peritonitis & 02 & $1.89 \%$ \\
\hline Cholangitis & 04 & $3.77 \%$ \\
\hline Electrolyte imbalance & 02 & $1.89 \%$ \\
\hline Pleural effusion & 02 & $1.89 \%$ \\
\hline Septicemia & 03 & $2.83 \%$ \\
\hline $\begin{array}{l}\text { Stent } \\
\text { occlusion/dislodgement }\end{array}$ & 02 & $1.89 \%$ \\
\hline Wound infection & 06 & $5.66 \%$ \\
\hline
\end{tabular}

It was seen that hospital stay was more in patients undergoing surgical bypass than in patients with endoscopic stenting but had lower complications and readmission rate. Complications in endoscopic and surgical groups were seen in 5 and 6 patients respectively while 2 patients in endoscopic group got readmitted because of recurrent complaints.

Table 7: Comparison of complications and readmissions in endoscopic and surgical group

\begin{tabular}{|l|c|c|}
\hline INTERVENTION & ENDOSCOPIC & SURGICAL \\
\hline Complications & 5 & 6 \\
\hline Readmission & 2 & O \\
\hline
\end{tabular}

\section{Discussion}

Obstructive jaundice poses diagnostic and therapeutic challenges to general surgeons and contributes significantly to high morbidity and mortality. The male to female ratio in this study was 1.2: 1. In case of benign causes it was 1.05:1 and in malignant diseases it was 1.3: 1. Girard $\mathrm{RM}^{10}$ found this to be 1: 1.72 with female preponderance. Zollinger ${ }^{11}$ stated that sex incidence is equal in both sex. This discrepancy can be explained by different rate of admission among male and female.

All 106 patients were having h/o jaundice. Blumgart ${ }^{12}$ stated that progressive jaundice is seen in $75 \%$ to $90 \%$ patients with periampullary malignancies. Hawkins and associates observed that jaundice is ominous finding in gallbladder carcinoma $^{13}$.

Pain in abdomen was the next most common symptom constituting $68.86 \%$. Pain was intermittent and colicky in patients with calculus diseases. Out of the 69 patients with malignant etiologies 43 patients had h/o pain in abdomen i.e. approximately $62.31 \%$. This is contradictory to the popular belief that painless jaundice occurs in malignancy. Pain in abdomen was the most common symptom observed by Mehrdad Moghimi et al,8 patients (7.54\%) were presented with $\mathrm{h} / \mathrm{o}$ lump in abdomen and 14 patients (13.20\%) were having $\mathrm{h} / \mathrm{o}$ distension of abdomen. Presence of a palpable lump is an ominous finding and predicts a high rate of unresectability and advanced disease.

Icterus was present in all patients. Evidence of cutaneous scratching secondary to pruritis was present in $41.50 \%$ patients. Hepatomegaly was present 40 patients constituting $37.73 \%$. Gall bladder was palpable in 42 patients. All these patients were having malignant etiologies. It showed that gallbladder was palpable in $60.86 \%$ cases with malignant obstructive jaundice, holding the Courvoisier's law good. Chalya et $\mathrm{al}^{15}$ appreciated palpable gallbladder in $50.9 \%$ patients with malignancy. Miller ${ }^{16}$ observed palpable gallbladder in $30 \%$ of patients in his series. Miller observed that $68.25 \%$ cases of Carcinoma of head of pancreas and $51.8 \%$ of periampullary carcinoma had palpable gallbladder. Lump was present in 8 patients $(7.54 \%)$ evidence of free fluid in abdomen was present in 8 patients. Blumgart ${ }^{17}$ stated that patients with disseminated pancreatic cancer may exhibit ascites, palpable hepatic metastasis

Ultrasound was done in all patients with fair sensitivity. In maximum patients it helped confirming the presence and level of obstruction. Harvey et $\mathrm{al}^{18}$ observed that initial USG is better than CT in patients with suspected acute biliary disease. Barloon et $\mathrm{al}^{19}$ stated that the sensitivity of ultrasound to dilatation of the bile ducts makes it the investigation of choice for the evaluation of jaundice. In this study ultrasound was found to be sensitive for prediction of resectability.

CECT abdomen was done in 83 patients (78.30 $\%)$. It was proved to be useful in defining the level of obstruction, demonstrating the presence of a pancreatic mass, and detecting liver metastases 
with $100 \%$ accuracy. Ishiguchi et $\mathrm{al}^{20}$ stated that advent of helical CT scanning enabled rapid evaluation of pancreas in different phases of contrast injection. Newer MDCT scanners have improved pancreatic imaging further with threedimensional image review in multiple projections $^{21}$. Other investigations such as MRCP, ERCP and biopsy were done only in selected cases. Vaishali et $\mathrm{al}^{22}$ observed that MRCP plays an important role in imaging benign disorders of biliary and pancreatic system and being part of a comprehensive imaging evaluation of malignancies of biliary system. It is noninvasive and eliminate the morbidity associated with $\mathrm{ERCP}^{23}$.

In this study of 106 patients, 25 patients had open CBD exploration. 17 of them underwent cholecystectomy with CBD exploration. Endoscopic stenting was done in 9 patients with CBD calculi. In a recent study by Edwina $\mathrm{N}$ et $\mathrm{al}^{24}$ concluded that the surgical double bypass is an efficacious means of palliating patients with locally advanced pancreatic adenocarcinoma.

Complications were seen in 25 patients $(23.58 \%)$. Surgical site infection was the most common complication which was seen in 6 patients which was controlled by antibiotics and wound dressings. Electrolyte imbalance, septicemia and pleural effusion was seen in 3 patients each. 3 patients with stenting and 1 patient who undergone PTBD had cholangitis. Stent dislodgement was seen in 2 patients and biliary peritonitis and anastomotic leak was seen in 2 patients each. It was seen that complication rate was more in patients who have undergone endoscopic palliation as compared to those who underwent surgical bypass. But endoscopic palliation is important in cases of elderly patients with malignant obstructive jaundice ${ }^{25}$.

\section{Conclusion}

Obstructive jaundice is a common surgical problem. Jaundice due to biliary obstruction may be caused by a heterogeneous group of diseases that include both benign and malignant conditions. The proper diagnosis and appropriate treatment is must as delay in treatment may cause the malignant growth to become unresectable (in malignant diseases). Even in benign conditions delay in management may cause irreversible pathological changes (secondary biliary cirrhosis in cases of biliary strictures).

\section{Conflict of Interest: None}

\section{Bibliography}

1. Lischen RN, Gibson RN,Carr DH et al. An appraisal of differential diagnosis of jaundice Surgery 1964; 55:473

2. AIRD I. A companion in surgical studiessecond edition E \& S Livingstone Ltd, Edinburgh \& London.

3. Koenraad J.Mortelé and Pablo R.Ros. Anatomic Variants of the Biliary Tree MR Cholangiographic Findings and Clinical Applications. American Journal of Roentgenology. 2001; 177: 389-394.

4. Lamah M. Anatomical Variations of the Extra hepatic Biliary Tree: Review of the World Literature. Clinical Anatomy 2001; 14: 167-172.

5. Rubin GD et al. 3-D Imaging with MDCT. European Journal of Radiology, 2003; 45(suppl I): S37-S41S.

6. Smits N, Reeders J. Current applicability of dupex Doppler ultrasonography in Pancreatic head and biliary malignancies. Bailliere's clinical gastroenterology: diagnostic imaging of the gastrointestinal tract, part II. Bailliere Tindell, London, 153-172.

7. Benjamin IS. Biliary tract obstruction Surgical gastroenterology 1983; 2:105120.

8. Desmet VJ. Cholestasis: extra hepatic obstruction and secondary biliary cirrhosis. Pathology of the Liver, Churchill Livingstone, 1979, London chapter 13.

9. Fletcher DR, et al. complications of cholecystectomy; risk of laparoscopic approach and protective effect of operative 
cholangiography. Annals of Surgery, 1999; 229:449-457

10. Girard RM, 2000: stones in common bikle duct: surgical approaches. In Blumgart LH, Fong Y (eds): Surgery of the Liver and Biliary tract and pancreas , 3 rd ed.Philadelphia,Saunders, p 737.

11. Zollinger W. Sugical aspects of Jaundice. Surgery 1956; 39: 1016.

12. Blumgart LH. Surgery of the Liver,Biliary tract and Pancreas. $4^{\text {th }}$ Edition.

13. Hawkins WG, et al. Jaundice predicts advanced disease and early mortality in patients with gallbladder cancer. Annals of Surgical Oncology, 2004; 11;310-315.

14. Mehrdad Moghimi, Seyed Ali Marashi, Mohammad Taghi Salehian and Mehrdad Sheikhvatan. Obstructive jaundice in Iran: factors affecting early outcome. Hepatobiliary Pancreatic Diseases International, 2008; 7: 515-519.

15. Phillipo L Chalya1, Emmanuel $\mathrm{S}$ Kanumba et al. Etiological spectrum and treatment outcome of Obstructive jaundice at a University teaching Hospital in northwestern Tanzania: A diagnostic and therapeutic challenges. BMC Research Notes 2011, 4:147.

16. Miller JR, Aggenstoss AH, Comfort AH. Malignant Obstructive Jaundice. Cancer, 1951; 4: 233.

17. Blumgart LH, Hadjis NS, Benjamin IS, Beazley RM. Surgical approaches to cholangiocarcinoma at confluence of hepatic ducts. Lancet, 1984; 14: 66-70.

18. Harvey RT, Miler WT. Acute Biliary disease: Initial CT and follow- up USG versus initial US and follow-up CT. Radiology, 1999; 213: 831-836.

19. Barloon $\mathrm{T}$ et al. Diagnostic imaging to identify the cause of jaundice. American Family Physician,1996; 54: 556-562.

20. Ishiguchi $\mathrm{T}$ et al. CT and MR imaging of pancreatic cancer. Hepatogastroenterology, 2001; 48: 923-927.
21. Johnson PT et al. Multidetector-row computed tomography with three dimensional volume rendering of pancreatic cancer: a complete preoperative staging tool using computed tomography angiography and volume rendered cholangiopancreatography. Journal of computer Assisted Tomography, 2003; 27: 347-353.

22. Vaishali MD et al. Magnetic resonance cholangiopancreatography in obstructive jaundice. Journal of Clinical Gastroenterology, 2004; 38: 839-840.

23. Christensen M. Complications of ERCP: a prospective study. Gastrointestinal Endoscopy, 2004; 60: 721-731.

24. Edwina N Scott, Giuseppe Garcea, Helena Doucas. Surgical bypass vs. endoscopic stenting for pancreatic ductal adenocarcinoma. HPB (Oxford). 2009 March; 11(2): 118-124.

25. Grönroos JM, Gullichsen R, Laine S, Salminen P. Endoscopic palliation of malignant obstructive jaundice in extremely elderly patients: plastic stent is enough. Minim Invasive Ther Allied Technol. 2010 Apr;19(2):122-124. 